\title{
O mundo depois: o surgimento de novos problemas
}

\author{
Maria Cândida Moraes*
}

\section{Resumo}

Para transformar e reconstruir esse mundo pós-pandemia é preciso uma política educativa humanizadora que abra novas vias de transformação da consciência humana e de inserção social. Política capaz de integrar os saberes científicos e os saberes poéticos experienciais nutridores do viver humano. Uma política educativa de natureza compensatória que garanta uma educação de qualidade para todos, em especial, à população socialmente marginalizada, associada a uma politica de resiliência, de resistência e de formação docente, que inclua novas estratégias curriculares descentralizadas e contextualizadas, capazes de construirem uma nova ecologia da aprendizagem humana que restaure a esperança nesse mundo depois.

Palavras-chave: crise, complexidade, política civilizatória, política educativa.

\section{The world after: the emergence of new problems}

\section{Abstract}

To transform and rebuild this post-pandemic world, we need humanizing educational politics that allow us to create new ways of achieving social integration and transformations in human consciousness. Politics capable of integrating scientific knowledge and experiential poetic knowledge nourishing human living. An educational policy of compensatory nature that guarantees a quality education for all, especially the socially marginalized population, associated with a policy of resilience, resistance, and teacher education, which includes new decentralized and contextualized curricular strategies, capable of building a new ecology of human learning that restores hope in this after world.

Keywords: crisis, complexity, civilizational policy, educational policy.

Doutora em Educação pela PUC de São Paulo. Professora aposentada da Universidade Católica de Brasília. Pesquisadora do GEPEC - Grupo de Estudos e Pesquisas em Complexidade, da UMESP. Profa. Convidada da Universidade de Barcelona. mariacandida4@gmail.com 


\section{El mundo después: la aparición de nuevos pro- blemas}

\section{Resumen}

Para transformar y reconstruir este mundo postpandemia, se necesita de una política educativa humanizadora que abra nuevas vías de transformación de la conciencia humana y la inserción social. Política capaz de integrar el conocimiento científico y el conocimiento poético experiencial que nutre la vida humana. Una política educativa de carácter compensatorio que garantice una educación de calidad para todos, especialmente para la población socialmente marginada, asociada a una política de resiliencia, resistencia y formación docente que incluya nuevas estrategias curriculares descentralizadas y contextualizadas, capaces de construir una nueva ecología del aprendizaje humano que restablezca la esperanza en este mundo después.

Palabras clave: crisis, complejidad, política civilizatória, política educativa

\section{Introdução}

Para poder falar de 'um mundo depois' é preciso compreender as crises que atualmente a humanidade vem enfrentando, ainda mais agravadas pela crise sanitária provocada pelo coronavirus, que fez com que a incerteza se apoderace da humanidade. Incerteza em relação à vida, aos afetos, ao futuro e à própria morte. Uma incerteza no viver/conviver provocada por um minúsculo vírus de origem desconhecida, que apareceu em Wuhan, na China e que acabou provocando uma catástrofe mundial.

A incerteza sempre esteve presente em nossas vidas, mas nem sempre estivemos conscientes de sua presença. Agora, ela está presente em todos os instantes do nosso viver/conviver. Presente no ar que se respira, na mão que acaricia, no abraço que fortalece. Certamente não sabemos quando esta pandemia irá regredir e se um dia realmente passará. Tudo o que existe são novas incertezas atormentando a vida do ser humano. E quando tudo isso termine, já não seremos mais os mesmos. A vida mudou e todos mudaram, seja para o bem ou para o mal.

Concordo com Capra e Handerson (2020), ao observarem que o coronavirus deve ser visto como uma resposta biológica de 
Gaia à emergência social e ecológica que a humanidade criou. Para eles, esta pandemia emergiu de um desequilíbrio ecológico e terá consequências dramáticas devido às desigualdades econômicas e sociais provocadas.

Assim, o termo crise está associado ao conceito de mudança, transformação e metamorfose, e traz consigo um caráter de dúvida, incerteza e emergência, associada à uma sensação de perigo em relação à sobrevivência humana. Neste caso, ao nos referirmos à essa crise civilizacional, percebemos, claramente, os sintomas de esgotamento e a presença de símbolos que a estão conduzindo a profundas transformações e que podem induzir, inclusive, a uma progressiva e definitiva destruição ou mesmo a sua substituição por algo que ainda não sabemos o que será. O caráter de incerteza, perigo ou negatividade que percebemos em toda crise vem também acompanhado de aspectos contraditórios e complexos, de forma que a imprevisibilidade de seus efeitos, resultados e repercussões em novos processos críticos são, geralmente, imprevisíveis. Isso tem levado muitos teóricos, entre eles, Edgar Morin, a dizer que todas as crises, tanto as que se referem às estruturas biológicas, psicossociais ou socioculturais, encerram em seu interior, tantos aspectos negativos como positivos. Positivos enquanto podem levar em direção às mudanças qualitativas e integradoras de velhas contradições e insuficiências do sistema, dando lugar, inclusive, a novos sistemas. Negativos, porque toda crise supõe perturbações funcionais, processos de desgaste, carências, contradições que dão origem a danos nas estruturas de conservação dos sistemas, podendo, inclusive, levá-lo à morte.

Esta crise sanitária se revelou como uma crise civilizacional de dimensões planetárias, que colocou em perigo toda a humanidade, lembrando-nos que somos, verdadeiramente, uma comunidade de destino, a qual bioecologicamente estamos todos interconectados. O processo de interdependencia desta pandemia é um bom exemplo de que, em realidade, o mundo padece do 'efeito mariposa'. Do outro lado do mundo alguém come mariscos 
infectados e três meses depois, toda a humanidade se encontra em quarentena, demonstrando que o mundo funciona em rede, como um sistema único global, onde tudo está interligado por mais insignificante que seja.

Em realidade, é uma crise com várias facetas, uma policrise que traz consigo múltiplas crises de diferentes dimensões: econômica, política, social, educacional, laboral, ecológica e existencial. Como crise política, social, laboral e econômica, ela abalou a economia, agravou o desemprego e aumentou as desigualdades. Vivemos hoje uma tragédia econômica sem precedentes, maior do que a grande recessão econômica de 1929.

Esta pandemia também provocou uma grande crise no mundo do trabalho, pois além das novas tecnologias e das inovações estarem, há tempos, exigindo novos perfis formativos, milhões de trabalhadores perderam seu emprego e, como sempre, os assalariados e as pequenas empresas serão os mais prejudicados. Em todo o mundo, milhões de pessoas estão sendo arrastadas de volta à pobreza, à fome e à miséria. Algo extremamente grave e sem precedentes na história mundial.

A crise atual é também uma crise de natureza ecológica provocada por ecopredadores que, há décadas, vêm saqueando a natureza e provocando mudanças climáticas. Ecologistas de todo o mundo vêm advertindo que a destruição humana da biodiversidade está criando condições que favorecem o aparecimento de novos vírus e novas enfermidades. A destruição da fauna e da flora da Amazônia Brasileira e do Pantanal Matogrossense têm provocado graves consequências e implicações no desenvolvimento de diferentes epidemias e no adoecimento e dizimação da população indígena brasileira. Além disto, a depredação e a invasão desses ecossistemas florestais pelo agronegócio criam situações desestabilizadoras do equilíbrio da natureza, podendo, inclusive, provocar a mutação acelerada de novos vírus, aumentando, assim, a possibilidade de novas propagações e infecções nos seres humanos. 


\section{Mudanças na ecologia da aprendizagem humana}

Associado aos problemas econômicos, sociais, ecológicos e existenciais estão também os problemas educacionais provocados por esta pandemia e que vem exigindo um reposicionamento imediato da educação para diminuir as consequências e os efeitos adversos nas comunidades e populações mais desprotegidas e carentes. São mudanças sociais, econômicas, políticas e culturais associadas à sociedade da informação e que também estão modificando profundamente os ambientes de ensino e aprendizagem, as situações e os contextos educativos. Todas essas mudanças vêm transformando a ecologia da aprendizagem humana, em especial, aquelas pautadas pela escolarização universal, única, homogênea e igual para todos.

Com as escolas fechadas, o setor educativo vem enfrentando grandes dificuldades, provocadas pelo confinamento geral acrescido pelos problemas econômicos, tecnológicos e operacionais. Pais, educadores e gestores estão cheios de dúvidas se as escolas devem ou não voltar às atividades presenciais sem terem descoberto uma vacina redentora. Além disto, o ensino à distância, improvisado de última hora, tem sido absolutamente questionado em termos de sua eficácia, em especial, no que se refere aos estudantes das comunidades mais vulneráveis. A maioria não tem internet e nem ambiente adequado de estudo. Grande parte dos alunos tem dificuldade para realizar atividades remotas, mesmo aqueles de classes mais abastadas. Muitos estão sofrendo problemas emocionais e físicos em função do isolamento social e do sedentarismo precoce, o que vem aumentando a ansiedade dos jovens e a obesidade infantil, além de vários outros efeitos colaterais graves provocados pelo avanço dessa pandemia no Brasil. O coronavírus acabou expondo e agravando as injustiças sociais, raciais e ecológicas omitidas, por décadas, pelas mídias sociais. Como proceder? Nesta pandemia, a justiça social revela-se, hoje, uma questão de vida ou morte.

Assim, pensar em uma nova ecologia da aprendizagem humana passou a ser um grande desafio desse mundo pós-pandemia. Uma nova urgência requerida pelas transformações ocorrentes 
nessa conjuntura mundial caótica e que vem afetando as práticas sociais, culturais, econômicas e, sobretudo, as nossas relações com a natureza. Querendo ou não, a pandemia igualou a todos em seus medos e em suas esperanças, em seus sofrimentos e desejos de seguir adiante vivendo/convivendo em um mundo melhor, emocionalmente mais saudável, socialmente mais justo e ecologicamente mais sustentável. E a cada dia, estamos mais impactados, impressionados e fragilizados com a transitoriedade da vida, desvelada de maneira impactante por esta pandemia e por nossas relações egocêntricas e destrutivas com a natureza.

Mas, como disse Edgar Morin, é preciso resgatar a esperança no improvável, fazendo com que o improvável dialogue com o provável, ou seja, com aquilo que o espírito humano imagina que possa acontecer. Em vez de regredir e destruir tudo, todas essas crises trazem também a possibilidade de que a imaginação criativa do ser humano seja colocada em ação, em busca de um novo caminho possível para todos os seres do planeta. Para Morin, a esperança não é uma certeza, pois ela cresce ao lado da desesperança.... mas ela pode surgir e abrir um novo caminho, que é o caminho da esperança nesse mundo pós-pandemia!

\section{O mundo depois e o surgimento de novos problemas}

A esperança nesse mundo pós-pandemia revela que o confinamento obrigatório diminuiu, em poucas semanas, a poluição na baía de São Francisco (EUA), nos canais de Veneza e no trânsito das grandes capitais do mundo, melhorando a qualidade do ar nos grandes centros urbanos. Com o planeta focado em combater a Covid-19, as emissões de gases de efeito estufa caíram consideravelmente como consequência da diminuição da atividade econômica, do cancelamento de vôos e da redução da frota automobilística. Tudo isso em um curto espaço de tempo.

Mas, assim como em outras situações críticas, os níveis desses gases provavelmente voltarão a atingir novos picos após a pan- 
demia, enquanto não mudarem essas políticas míopes que geraram esses colapsos sociais e ecológicos, a fome, a pobreza, as desigualdades, as doenças físicas e mentais. Se nada for feito, novos e sérios problemas econômicos, sanitários e ecológicos continuarão surgindo de tempos em tempos, resultantes da derrubada das florestas pela mão humana e pela fragmentação dos ecossistemas autorregulatórios que fraturam a rede da vida.

As lições básicas deste momento trágico da pandemia estão ai para quem quiser e puder ver. Elas estão exigindo novas políticas civilizatórias para o encontro de possíveis soluções aos graves problemas emergentes, para o florescimento de novas ideias, de novos padrões éticos baseados tanto na ciência como no diálogo com a sabedoria das grandes tradições.

Mas, talvez, também possamos ter esperança de que uma outra consciência mais evoluída possa também emergir a partir de todas essas crises associadas às grandes perdas de vidas humanas. Em realidade, nesse mundo pós-pandemia, tudo pode acontecer, até mesmo a regeneração da humanidade e a evolução da consciência humana. Esta é, sem dúvida, a nossa grande esperança!

Tanto o mundo pode evoluir em direção a um novo caminho civilizatório de natureza política, ecológica, econômica e social, como também pode estagnar ou regredir em termos de democracia, demagogia, racismo, xenofobia e corrupção. Todas as possibilidades existem, mas temos também a esperança de que esta grande sacudidela que esta crise sanitária provocou na humanidade poderá favorecer o surgimento de um novo caminho guiado por um novo humanismo, capaz de promover as reformas civilizatórias da sociedade, da economia, da educação, da saúde, todas elas dirigidas às reformas para um bem-viver.

Mas, para tanto, é preciso evitar que todas essas crises acabem gestando uma "cultura de normalidade", ou uma cultura negacionista, que faça com que o ser humano já não se surpreenda por nada, que fique insensível ao número de mortes por covid-19 e que, neste final de setembro de 2020, chegou a mais de 1.000.000 
(hum milhão) de vítimas. Esta cultura de normalidade, ou 'normose', segundo Pierre Weil, corrói nossa capacidade de indignação e de mobilização, criminaliza a luta contra a injustiça e amortece nossa sensibilidade e compaixão. Ela nos faz cegos e surdos a essa desordem mundial estabelecida e, pouco a pouco, vai minando a nossa capacidade de indignação, resistência, esperança e luta. Essa aparente sensação de normalidade favorece o pensamento único, a passividade, a indolência e a irresponsabilidade e vem acompanhada de uma 'cultura de cinismo' que aceita a mentira, a corrupção, a incoerência e a manipulação. Em realidade, é o que está acontecendo em vários países do mundo, incluindo, o Brasil.

\section{Políticas civilizatórias para um mundo depois: em busca de possíveis soluções}

Para transformar e reconstruir esse mundo pós-pandemia é preciso uma política civilizatória pautada na ética da solidariedade e na responsabilidade social. Uma política capaz de encontrar soluções até agora desconhecidas e adotar estratégias que abram novos caminhos que vão além do local e nacional. Necessitamos de novas vias civilizatórias, como sinalizado por Morin, em que é preciso tecer, de modo complementar e diversificado, as dimensões pessoais e vitais junto às dimensões locais, nacionais, continentais e planetárias. Para tanto, é preciso mudar, não somente de perspectivas e enfoques, mas também as visões e concepções que, ao mesmo tempo em que articulem uma nova forma de ver o mundo e de viver/conviver, sejam também capazes de reconstruir valores éticos estratégicos e essenciais.

Necessitamos, nas palavras de Edgar Morin, que o pensamento humano e, especialmente, o pensamento político se complexifique para que possamos ver a história, os acontecimentos e a realidade presente em seus contextos, com suas interações, retroações e recursões. Isso requer uma mudança paradigmática capaz de reconhecer a realidade em sua multidimensionalidade e de proporcionar a compreensão de nossa condição humana paradoxal 
e contraditória. Uma mudança capaz de construir um novo fundamento ético, pautado na solidariedade, na responsabilidade social e ecológica, na sensibilidade humanitária e na inteligência emocional e que, junto com a razão ilustrada, possa desenvolver uma solidariedade intergeracional associada à compaixão em relação a todos os seres. Urge uma revolução ética mundial.

Neste sentido, a educação tem um papel fundamental e imprescindível e esse desafio tem a ver com a própria essência educativa, no sentido de converter-se em um processo permanente de ação transformadora e que é, ao mesmo tempo, individual e social. Todo processo educativo necessita ser permanentemente um processo interminável de humanização e socialização. Algo que ensine as pessoas não apenas a ler, a escrever e a contar, mas também a enfrentar as injustiças, as desigualdades e os problemas da realidade em que vivem, ao mesmo tempo, em que contribuem para sua melhoria e para o desenvolvimento de sua própria humanidade.

Para tanto, é preciso uma educação para viver e conviver baseada no compromisso de compartilhar, oferecer, dar e semear atendendo aos princípios de solidariedade e de responsabilidade. A educação é parte dessa metaestratégia civilizatória e humanizadora constituída por diversas vias de transformação, capaz de catalisar os poderes criativos e as necessidades de expressão e realização que levamos dentro de cada um de nós.

Para conceber uma política educativa de civilização é necessário complexificar tanto os nossos pensamentos como nossas ações, no sentido de contextualizar, integrar, multidimensionalizar e, sobretudo, humanizar a nossa existência, fundando-a na ética e no pathos como fonte de afeto, confiança e amor. Não apenas complexificar o pensamento político, mas também o pensamento educativo, todavia aprisionado em gaiolas epistemológicas, rotinas pedagógicas, burocracias institucionais que impedem o desenvolvimento da responsabilidade social da educação e sua missão transcendental de ampliar os níveis de consciência dos indivíduos visando maior integração e maturidade humana. 
Para tanto, é preciso levar em consideração os quatros eixos de política civilizatória propostos por Edgar Morin (2009, p.65): politica de solidariedade, política de qualidade de vida, política de regeneração, política de resistência e de restauração da ética e da esperança. Quais seriam os efeitos educativos dessas políticas? Que implicações teriam esses quatro grandes eixos estratégicos de transformação civilizatória em um mundo pós-pandemia?

Tendo em vista a problemática educacional agravada durante a pandemia, principalmente, em relação às crianças de famílias mais desfavorecidas, entendemos que uma política educativa baseada na solidariedade e na responsabilidade requer, de imediato:

1. Políticas compensatórias - que protejam e garantam o direito a uma educação de qualidade às crianças marginalizadas socialmente, no sentido de promover e assegurar a plena e efetiva igualdade de oportunidades para todos, eliminando todo o tipo de discriminação educativa ligada à origem social. É preciso garantir bolsas escolares e familiares, condições de infraestrutura de telecomunicações, já que o ensino do futuro deverá ser híbrido, com parte presencial e outra virtual. É preciso pensar as políticas de educação não apenas analisando os índices de exames nacionais e internacionais, mas observá-los à luz das desigualdades sociais, de modo a garantir as condições necessárias de nível socioeconômico, raça e gênero, lembrando que equidade se faz dando mais a quem precisa. Nesse sentido, as políticas compensatórias são fundamentais, urgentes e necessárias. Melhores professores, materiais didáticos e infraestruturas tecnológicas devem ser direcionados àqueles alunos de periferia e de zona rural que apresentem maiores dificuldades de aprendizagem. É preciso, pois, conceber infraestruturas e projetos de escolarização descentralizados, localizados e estreitamente vinculados à vida e à atividade social das comunidades, empoderando as famílias, o professorado 
e todos os agentes da sociedade que, de uma maneira ou de outra, incidem e participam da educação.

2. Políticas de resiliência - no sentido de desenvolver capacidades que ajudem os sujeitos a superar as adversidades, as situações e os momentos difíceis, como é o caso desta pandemia, cuja perda inesperada de entes queridos provoca um vazio existencial difícil de ser preenchido. Políticas de resiliência que ajudem a compreender que vida e morte são dois processos complementares, partes de um único e mesmo processo que é o "processo de viver". Políticas de resiliência, tanto em nível individual como coletivo, que ajudem a retomada de um novo processo de desenvolvimento após um evento traumático como é o caso desta pandemia, que possibilitem condições que facilitem o enfrentamento das situações de sofrimento, o fortalecimento interior e a transformação pessoal.

Desta forma, a educação tem um papel fundamental no sentido de disponibilizar espaços de fala que favoreçam os encontros e os apoios necessários, além da criação de espaços privilegiados que oportunizem o desenvolvimento de outras habilidades restauradoras do espírito, como as expressões artísticas, esportivas e meditativas, capazes de darem sustentação emocional e afetiva que leve à saída da imobilidade e a construção de um novo sentido de vida.

3. Politicas de formação de professores e gestores, com estratégias que melhorem e sustentem a responsabilidade e o compromisso profissional e vocacional do professorado, em especial, daqueles de educação fundamental. Políticas que favoreçam a satisfação de suas necessidades básicas e existenciais, a melhoria das condições de trabalho, a partir de sistemas de formação e aperfeiçoamento docente.

4. Estratégias curriculares descentralizadas que levem em conta as características e necessidades de cada contexto, que 
estimulem o desenvolvimento de capacidades humanas, mas também de competências e habilidades para se viver/ conviver nesse mundo complexo e mutante. Um currículo com múltiplas entradas e saídas, estruturado de forma orgânica e rizomática, aberto às aprendizagens que dialogam com as experiências de vida dos jovens e com as necessidades das comunidades. Um currículo integrado, em movimento, sem um final predeterminado, mas como uma rede de relações que se organiza de maneira rizomática, à medida que o processo educativo avance.

5. Escolas como comunidades de aprendizagem e de solidariedade. Aprendizagem do pensamento crítico e criativo, comprometidas com as necessidades da comunidade local, regional, nacional e planetária, dotadas de estruturas organizacionais flexíveis e adaptadas às peculiaridades de cada contexto, de forma que se possa praticar efetivamente o diálogo a participação, a colaboração, a cooperação entre todos os seus membros.

Em relação às políticas de qualidade de vida, Edgar Morin informa que elas deverão observar, pelo menos, três princípios: um ecológico, outro convivencial e outro de complementariedade entre prosa e poesia, de tal modo que os todos se complementem, a partir da qualidade das comunicações e das interações desenvolvidas (MORIN, 2011, p.70). Consequentemente, uma política de qualidade de vida tem que estar orientada a vários tipos de ecologia capazes de integrarem, ao mesmo tempo, tais princípios. A ecologia meio-ambiental que nos liga à natureza e ao ambiente; a ecologia social que nos vincula à comunidade e ao contexto social mais próximo e a ecologia humana que é, ao mesmo tempo, corporal, cognitiva, emocional e espiritual e a partir da qual exercemos nosso ser e estar no mundo como humanos integrados à dinâmica indivíduo/sociedade/natureza. De um modo geral, hoje existe uma cegueira em relação à qualidade de vida, pois sofremos de intoxicação consumista e de um estresse cada vez maior que nos impede de auscultar nosso mundo interior. 
Assim, uma política educativa centrada na qualidade de vida deve, portanto, assegurar recursos, condições, formação, infraestrutura e qualificação docente, mediante estratégias e projetos que deem respostas a esses diferentes tipos de ecologia, a partir dos seguintes aspectos:

1. Educação ecológica - não apenas visando aspectos conceituais, mas sobretudo atitudinais, a partir de realização de experiências baseadas na ética do cuidado, do compromisso com a sustentabilidade e com todo tipo de estratégias pedagógicas que ajudem a reutilizar, reciclar e reduzir os insumos. Uma educação ecológica voltada ao conhecimento ativo, experiencial e reverencial em relação ao mistério da natureza e que denuncie problemas sociais gerados pelo consumo de agrotóxicos, por agentes contaminantes das águas, dos produtos transgênicos etc. Uma educação que promova a reconexão do indivíduo com a natureza e com o milagre da vida, a reverência diante do mistério e do sagrado que se aninha em cada uma das conexões das redes que abriga todas as criações.

2. Educação social vinculada às relações com a família, o bairro, a comunidade e como construção ecológica de vínculos humanitários de solidariedade e responsabilidade e que configuram formas de comunicação baseada no diálogo, na compreensão, na tolerância e no respeito. Ume educação social integradora das diversidades culturais, geradora de interdependências e criadora de relações emocionais saudáveis e colaborativas.

3. Educação corporal, cognitiva, emocional e espiritual - que nos ajude a conhecer, compreender e sentir o próprio corpo como fonte permanente de bem-estar, equilíbrio e harmonia, desenvolvendo, ao mesmo tempo, todas as suas possibilidades, visando o alcance de níveis mais integrados de bem-estar biopsicofísico. Uma 
educação corporal que estimule e motive em direção a estilos de vida e atitudes mais saudáveis, em busca de harmonia física e espiritual. Uma educação cognitiva capaz de dotar o ser humano de ferramentas, não apenas para conhecer a realidade e a si mesmo, mas também no sentido de habilitá-lo para processar as informações e construir conhecimento. Que estimule e promova o exercício do pensamento crítico, que ensine a perguntar, a investigar e a questionar-se. Uma educação cognitiva que o leve a aprender a relacionar, a contextualizar e a integrar o diverso em unidades mais integradoras e complexas; que promova o pensamento complexo, integrador e relacional, que o ajude a viver na incerteza e a dialogar com as emergências da vida. Uma educação espiritual baseada no reconhecimento da multidimensionalidade do ser humano e da vida e que perceba que a realidade última não pode ser descrita, nem explicada e nem representada. Uma educação espiritual que se construa a partir dos valores culturais, éticos e humanos herdados das grandes tradições espirituais, capaz de favorecer a escuta da sombra e do silêncio e a descobrir novas perspectivas estéticas, poéticas e místicas da realidade.

4. Educação política - dirigida a conhecer, desenvolver e aplicar atitudes e procedimentos democráticos de convivência, a partir da consciência de que a democracia, mais do que uma fórmula aritmética para a representação e tomada de decisões coletivas é, antes de tudo, uma atitude e um processo permanente de conquista de liberdade, autonomia e responsabilidade.

5. Educação tecnológica - As redes sociais vieram para ficar e daqui para frente, terão um papel relevante na organização da vida educacional, política e social do país. Um papel que não pode ser ignorado, pois as atuais tecnologias da informação e da comunicação são um fa- 
tor revolucionário de profundas consequências na vida política, cultural, educativa e social do cidadão/ã. Um dos grandes problemas ético e moral provocado por esta pandemia foi a desigualdade no acesso à informação, aumentando a exclusão automática de imensa maioria da população brasileira. A dificuldade de acesso às informações aumentou as desigualdades educacionais de maneira aviltante, algo que precisa ser corrigido com urgência. É preciso educar os jovens no uso dessas tecnologias, lembrando que elas, mais do que nunca, colaboram para a criação de uma nova ecologia da aprendizagem humana.

\section{Concluindo}

Diante da conjuntura política atual só nos resta resistir e atuar a partir do $\mathrm{m}^{2}$ que cada um pisa. Resistir no sentido de continuar semeando a possibilidade de mudança interior e de transformação social. Resistir para que o novo possa nascer, inclusive, das próprias sementes da destruição. Para resistir, é preciso confiar, ter fé e esperança no ser humano apesar da desesperança tão presente em nossas vidas. Para tanto, é necessário olhar para o futuro com um mínimo de clarividência e confiança no amanhã, cultivar a esperança e a fé na humanidade.

Urge, então, que desde nossas escolas, os alunos sejam educados na fé nos seres humanos e para isso é necessário e importante ter professores apaixonados por sua profissão, ansiosos por descobrir a cada dia e a cada instante qual é a melhor, mais adequada e mais divertida forma de ajudar seus alunos a aprender e a se desenvolver humanamente. Para tanto, é preciso políticas administrativas e de gestão para que o professorado se sinta protegido, valorizado e estimulado para que a chama de amor por sua profissão e de sua fé na educação esteja sempre viva e disposta a iluminar os processos de desenvolvimento e de transformação de seus alunos.

Concluindo, destacamos as palavras premonitórias de Edgar Morin, em seu livro Terra-Pátria, lembrando que: 
"A tomada de consciência da comunidade de destino terrestre deve

ser o acontecimento-chave do fim do milênio: sejamos solidários com este planeta, a nossa vida está ligada à sua vida. Ou o salvamos

ou morreremos. Assumir a cidadania terrestre é assumir a nossa comunidade de destino (MORIN, 2001, p.203).

\section{Referências}

BATAlLOSO Juan Miguel; MORAES, Maria Cândida. Por una política de civilización y regeneración de la humanidad: algunas implicaciones educativas. Mimeo. 2011.

CAPRA, Fritjof; HENDERSON, Hazel. A pandemia vista de 2050. Revista Fronteiras do Pensamento/UNISINOS. https://www.fronteiras.com/artigos/fritjof-capra-e-hazel-henderson-a-pandemia-vista-de-2050?. Acessada em 20 de setembro de 2020 .

MORAES, Maria Cândida. Ecologia dos saberes: complexidade, transdisciplinaridade e educação. São Paulo: Antakarana,2008.

MORIN, Edgar; KERN, Anne Brigitte. Terra-Pátria. Lisboa: Instituto Piaget, 2001.

MORIN, Edgar. Para una política de la civilización. Barcelona: Paidós, 2009.

MORIN, Edgar. Rumo ao abismo: ensaios sobre o destino da humanidade. Rio de Janeiro: Bertrand Brasil, 2011.

MORIN, Edgar. O pensamento do sul. SESC/RJ:2011.

MORIN, Edgar. La vía: para el futuro de la humanidad. Barcelona: Paidós, 2011.

MORIN, Edgar. Ensinar a viver: manifesto para mudar a educação. Porto Alegre: Editora Sulina, 2015. 